\title{
Banking Firm, Equity and Value at Risk
}

\author{
Udo Broll', Anna Sobiech'1 \& Jack E. Wahl²
}

\begin{abstract}
The paper focuses on the interaction between the solvency probability of a banking firm and the diversification potential of its asset portfolio when determining optimal equity capital. The purpose of this paper is to incorporate value at risk (VaR) into the firm-theoretical model of a banking firm facing the risk of asset return. Given the necessity to achieve a confidence level for solvency, we demonstrate that diversification reduces the amount of equity. Notably, the VaR concept excludes a separation of equity policy and asset-liability management.
\end{abstract}

KEY WORDS: $\quad$ financial markets, equity capital, banking, value at risk (VaR), diversification, risk management, asset-liability management

JEL Classification: G21, G28

${ }^{1}$ Dresden University of Technology, Germany ${ }^{2}$ Dortmund University of Technology, Germany

\section{Introduction}

Many years ago, most of the banking literature focused on either monetary issues or management problems of banking, with no connecting link. Since then, a microeconomic theory of banking and finance has developed, mainly through a shift in emphasis from the modeling of risk and asymmetric information to the modeling of financial regulation. One instrument of bank regulation is the value at risk concept.

The value at risk $(\mathrm{VaR})$ of a portfolio measures the loss in its market value over a risk horizon that is exceeded by a small probability. Bank management can apply VaR to set capital requirements based on an estimate of capital loss due to the market and credit risk (see, e.g., (Bessis, 2002; Duffie \& Pan, 1997; Freixas \& Rochet, 2008; Frenkel, Hommel \& Rudolf, 2005; Jorion, 2006; Saunders \& Allen, 2002; Simons, 2000). The purpose of this paper is to incorporate value at risk into the firm-theoretical model of a banking firm.

Corespondence concerning this article should be addressed to: Udo Broll, Technische Universität Dresden, Fakultät Wirtschaftswissenschaften Lehrstuhl für Volkswirtschaftslehre, insb. Internationale Wirtschaftsbeziehungen 01062 Dresden, e-mail:broll@msx.tu-dresden.de
The objective of our study is to determine the optimal amount of equity capital of a banking firm.

Institutionally, bank regulations mandate that banks using VaR models set aside equity capital for the market risk related to financial operations using a relatively short risk horizon and a significantly high confidence level. Risk management must link this issue to financial views about risk and profitability. In our decision model of a banking firm, the financial objective is to maximize the value of the firm in a competitive financial market environment (see, e.g., Freixas \& Rochet, 2008; Greenbaum \& Thakor, 2007; Wong, 1997; Wong, 2011). The return on the bank's portfolio of assets is risky. The banking firm is exposed to market risk and therefore may not be able to meet its debt obligations.

Instead of mitigating the banking firm's exposure to risk the management can use hedging instruments such as financial derivatives (see, for example, Broll \& Wong, 2010; Broll, Eckwert \& Eickhoff, 2012; Czarniawska, 2012). In our study, we incorporate the VaR concept into the present model as a risk management tool to analyze the solvency status of the banking firm.

The purpose of our study is to incorporate the VaR concept into the firm-theoretical model of a banking firm to determine how much equity capital the banking firm 
should hold. The optimal amount of equity depends on institutional and market variables. The confidence level set by the regulator and the correlation of risky returns of the assets within the bank's portfolio have a nontrivial relationship. In particular, the VaR concept excludes a separation of equity policy and asset-liability management.

We demonstrate that by studying the asset portfolio market and institutional factors, it is possible to determine the bank's optimal equity and asset-liability management policies. Given the institutional requirement to achieve a higher confidence level of solvency, the banking firm can either increase its equity capital base or improve the diversification potential of its asset portfolio. Hence there is a trade-off between equity and diversification.

The remainder of the paper is organized as follows. First, we present the firm-theoretical model of a bank facing the risk of return. We focus on financial regulation and the VaR approach to setting aside equity capital for market risk. Second, we examine the bank's optimal equity policy and asset-liability management. We present conclusions in the final section.

\section{The model}

Consider a bank that makes decisions in a single period horizon with two dates, 0 and 1 . The banking firm invests in two risky assets to the extent that $A_{1} \geq 0$ and $A_{2} \geq 0$. At the beginning of the period, the returns on the assets, $\tilde{r}_{A_{1}}$ and $\tilde{r}_{A_{2}}$, are random. The bank's portfolio is financed by deposits, $D$, and equity capital, $K$. The bank's deposits are insured by a government-funded deposit insurance program. The supply of deposits is perfectly elastic at the fixed deposit rate, $r_{D}$. The bank's operating costs occur at the beginning of the period. The compounded cost function $C(D)$ is doubly and continuously differentiable and has the properties $C^{\prime}(\cdot)>0$ and $C^{\prime \prime}(\cdot)>0$ whenever $D>0$.

The bank's shareholders contribute equity capital. Optimal decision making by the bank's management has to satisfy the balance sheet identity

$$
A_{1}+A_{2}=D+K
$$

Given that the bank's assets have risky outcomes, there is some probability for the insolvency of the banking firm.

If the bank's loss in market value of its asset portfolio does not exceed equity capital at the confidence level $1-\alpha$, then $\mathrm{VaR}_{\alpha}$ measures the maximum amount of that loss at date 1. Therefore, $K=\mathrm{VaR}_{\alpha}$ implies that the bank is not able to meet its debt obligations with the probability $\alpha$. Hence, $\alpha$ measures the probability of bankruptcy of the banking firm. In the event of insolvency, equity holders have to relinquish their property rights to depositors.

The bank's risky end-of-period profit, $\tilde{\Pi}$, can be stated as follows:

$\tilde{\Pi}=\tilde{r}_{A_{1}} A_{1}+\tilde{r}_{A_{2}} A_{2}-r_{D} D-C(D)$.

Bank management maximizes the value of the banking firm by satisfying the bank's balance sheet identity (1). Applying the VaR risk management approach, i.e., $K=\mathrm{VaR}_{\omega}$, management chooses the amount of equity capital by

$\max _{K} E(\tilde{\Pi})$

s.t.

$A_{1}+A_{2}-D=\mathrm{VaR}_{\alpha}$

where $E$ denotes the expectation operator, and the banking firm's risky profit is determined by equation (2).

We assume that bank management assesses the market risk by presuming a binormal distribution of the random returns with the expected returns, $\mu_{A_{1}}$ and $\mu_{A_{2}}$, respectively, the standard deviations of returns, $\sigma_{A_{1}}$ and $\sigma_{A_{2}}$, respectively, and the correlation of risky returns, $\rho$.

We derive the value of risk measurement in our economic setting. The probability of bankruptcy is given by $\operatorname{prob}\left(-\left(\tilde{r}_{1} A_{1}+\tilde{r}_{2} A_{2}\right)>K\right)>0$, where $\tilde{r}_{j}=\left(\tilde{r}_{A_{j}}-r_{D}\right) /\left(1+r_{D}\right), j=1,2$ (see appendix 1$)$. Hence, there is a positive probability that at the end of the period, the loss in market value of the bank's asset portfolio may exceed the volume of equity capital of the banking firm. The degree of this probability has to be chosen by management and/or is set by bank regulations.

We obtain the following solvency condition:

$\operatorname{prob}\left(-\left(\tilde{r}_{1} A_{1}+\tilde{r}_{2} A_{2}\right) \leq K\right)=1-\alpha$.

The random variables $\tilde{r}_{1}$ and $\tilde{r}_{2}$ are binormally distributed with the expected values $\mu_{j}=E\left(\tilde{r}_{j}\right)=\left(\mu_{A_{j}}-r_{D}\right) /\left(1+r_{D}\right)$ and standard deviations $\sigma_{j}=S\left(\tilde{r}_{j}\right)=\sigma_{A_{j}} /\left(1+r_{D}\right), j=1,2$, where $S$ denotes the standard deviation operator. 
Assumption (A.1). Suppose that both assets of the banking firm exhibit identical expected returns, i.e., $\mu_{A_{1}}=\mu_{A_{2}}$, and identical standard deviations of return, i.e., $\sigma_{A_{1}}=\sigma_{A_{2}}$.

This assumption implies that: $\mu_{1}=\mu_{2} \equiv \mu$ and $\sigma_{1}=\sigma_{2} \equiv \sigma$. It follows that the solvency condition (5) can be stated as

$r_{\alpha \rho}\left(A_{1}+A_{2}\right)=K$

where $r_{\alpha \rho}=-\left(\mu+u_{\alpha} \sigma \sqrt{\frac{1+\rho}{2}}\right)>0$, and $u_{\alpha}$ is the $\alpha$-frac-

tile of the unit of normal distribution (see appendix 2).

The magnitude $r_{\alpha \rho}$ represents the value at risk of a risky investment of one dollar in the portfolio. This magnitude is inversely related in the probability of bankruptcy, $\partial r_{\alpha \rho} / \partial \alpha<0$, and increases with the correlation coefficient, $\partial r_{\alpha \rho} / \partial \rho>0$. VaR is determined by multiplying the portfolio investment amount with the unit VaR: $\operatorname{VaR}_{\alpha}=r_{\alpha \rho}\left(A_{1}+A_{2}\right)$.

\section{Optimal equity capital}

In the following section, we discuss the impact of diversification on the optimal amount of equity capital. To arrive at a reduced form of optimal equity capital volume, we specify the cost function of financial intermediation.

Assumption (A.2). Suppose that the financial intermediation cost function is quadratic and of the form $C(D)=\theta D^{2} / 2, \theta>0$.

Taking into account all the definitions and constraints of the above section and the specified cost function, the banking firm's expected risky profit (2) $\operatorname{reads}\left(\mu_{A_{1}}=\mu_{A_{2}} \equiv \mu_{A}, \operatorname{see}(A .1)\right)$ :

$E(\tilde{\Pi})=\frac{1}{r_{\alpha \rho}}\left[\mu_{A}-\left(1-r_{\alpha \rho}\right) r_{D}\right] K-\frac{\theta}{2}\left(\frac{1-r_{\alpha \rho}}{r_{\alpha \rho}}\right)^{2} K^{2}$.

In our economic setting, expected profit can be stated only as a function of the bank's equity capital.

We claim the following propositions.

Proposition 1 (Equity) Risk management by VaR under market value maximization implies that the optimal amount of equity capital depends on

(i) market factors such as the deposit rate and the intermediation costs, and

(ii) institutional factors such as the confidence level and the bivariate probability distribution of returns on risky assets.
Notice that the correlation between the assets' returns is of particular interest in our study.

Proof Maximizing equation (7) for equity $K$ leads to:

$K^{*}=r_{\alpha \rho} \frac{\mu_{A}-\left(1-r_{\alpha \rho}\right) r_{D}}{\theta\left(1-r_{\alpha \rho}\right)^{2}}$.

This proves the proposition.

Our first result reveals that the optimal equity $K^{*}$ can be determined explicitly. Herein, unit VaR $r_{\alpha \rho}$ plays a crucial role.

Proposition 2 (Solvency) If the required confidence level $1-\alpha$ is augmented, then equity base $K^{*}$ has to be increased for the optimal, cet. par.

Proof From equation (8), it follows that interior solutions require a positive expected margin $\mu_{A}>\left(1-r_{\alpha}\right) r_{D}$ and $r_{\alpha \rho}<1$. Because $r_{\alpha \rho}$ decreases in $\alpha$, it follows that $K^{*}$ decreases in $\alpha$, i.e., $\partial K^{*} / \partial \alpha<0$.

If bank regulations institutionally set a higher (lower) confidence level, the owners of the bank have to contribute more (less) equity capital to enable bank management to realize an optimal asset-liability policy. Furthermore, in an optimal bank policy under VaR, assets and liabilities management has to be undertaken simultaneously. Notice that $D^{*}=K^{*}\left(1-r_{\alpha \rho}\right) / r_{\alpha \rho}$.

Proposition 3 (Diversification) If the correlation of assets' returns $\rho$ decreases, then the optimally required amount of equity capital $K^{*}$ becomes smaller, cet. par.

Proof Given the interior solutions (see proof of Proposition 2) from equation (8), we obtain $\partial K^{*} / \partial \rho>0$.

The correlation coefficient measures the diversification potential of the assets portfolio. If the risky returns correlation of assets $A_{1}$ and $A_{2}$ becomes smaller, then portfolio risk diminishes. Therefore, a given confidence level can be achieved with less equity capital. Hence, there exists a trade-off between the optimal amount of equity capital and the risk minimizing potential of the assets portfolio of the banking firm.

Conversely, if a higher confidence level must be satisfied institutionally, a banking firm could adjust its assets portfolio instead of increasing the equity base. In this instance the bank would have to exchange its assets for other assets that are less correlated with returns while keeping the required optimal amount of equity capita constantl.

Notably, our analysis is based on risk neutrality. However, diversification is important for discussing the optimal amount of equity capital utilizing the VaR approach. 


\section{Concluding remarks}

Instead of mitigating the the banking firm's exposure to risk by using hedging instruments, we incorporate the value at risk (VaR) concept as a risk management tool to analyze the solvency status of the banking firm. We demonstrate that by studying the asset portfolio market and institutional factors, it is possible to determine the bank's optimal equity policy and asset-liability management.

The purpose of our paper is to incorporate the VaR concept into the firm-theoretical model of a banking firm facing the risk of asset return to determine how much equity capital the banking firm should hold. The optimal amount of equity depends on market and institutional factors, such that the confidence level set by the regulator and the correlation of risky returns of the assets within the bank's portfolio have a nontrivial relationship with this amount (Propositions 1, 2 and 3). Notably, the VaR concept excludes a separation of equity policy and asset-liability management.

\section{Appendix 1}

Bankruptcy risk is defined by

$\operatorname{prob}\left(A_{1}\left(1+\tilde{r}_{A_{1}}\right)+A_{2}\left(1+\tilde{r}_{A_{2}}\right)-D\left(1+r_{D}\right)<0\right)>0$.

From the balance sheet constraint, this condition is equivalent to

$\operatorname{prob}\left(A_{1}\left(1+\tilde{r}_{A_{1}}\right)+A_{2}\left(1+\tilde{r}_{A_{2}}\right)-\left(A_{1}+A_{2}-K\right)\left(1+r_{D}\right)<0\right)>0$, which in turn becomes

$\operatorname{prob}\left(A_{1}\left(1+\tilde{r}_{1}\right)+A_{2}\left(1+\tilde{r}_{2}\right)-A_{1}-A_{2}+K<0\right)>0$, using $1+\tilde{r}_{j}=\left(1+\tilde{r}_{A_{j}}\right) /\left(1+r_{D}\right), j=1,2$. It follows that $\operatorname{prob}\left(-\left(\tilde{r}_{1} A_{1}+\tilde{r}_{2} A_{2}\right)>K\right)>0$.

\section{Appendix 2}

If $\tilde{x}$ is normally distributed with the expected value $\mu_{x}=E(\tilde{x})$ and variance $\sigma_{x}^{2}=V(\tilde{x})$, then the $N\left(\mu_{x}, \sigma_{x}^{2}\right)$ -fractile of order $\alpha$ is defined by

$\operatorname{prob}\left(\tilde{x} \geq x_{\alpha}\right)=1-\alpha$,

where $x_{\alpha}=\mu_{x}+u_{\alpha} \sigma_{x}$, and $u_{\alpha}$ is the $N(0,1)$-fractile of order $\alpha$.

Because $\mu_{x}$ represents the expected portfolio return in our model and $\sigma_{x}$ the standard deviation of the portfolio return, it follows: (i) the expected portfolio return in dollars reads $\mu\left(A_{1}+A_{2}\right)$, and (ii) the standard deviation of the portfolio return in dollars reads

$\sigma\left(A_{1}^{2}+A_{2}^{2}+2 \rho A_{1} A_{2}\right)^{1 / 2}=\left(\frac{1+\rho}{2}\right)^{1 / 2}\left(A_{1}+A_{2}\right)$ because in

the optimum we have $A_{1}=A_{2}$.
Hence, the solvency condition (5) for a normally distributed $\tilde{r}_{1} A_{1}+\tilde{r}_{2} A_{2}$ becomes

$\operatorname{prob}\left(\frac{\tilde{r}_{1} A_{1}+\tilde{r}_{2} A_{2}}{A_{1}+A_{2}} \geq-\left(\frac{K}{A_{1}+A_{2}}\right)_{\alpha}\right)=1-\alpha$.

It follows that $-\left(K /\left(A_{1}+A_{2}\right)\right)_{\alpha}=\mu+u_{\alpha} \sigma \sqrt{\frac{1+\rho}{2}}$,

where $\mu=E\left(\tilde{r}_{1}\right)=E\left(\tilde{r}_{2}\right)$ and $\sigma=S\left(\tilde{r}_{1}\right)=S\left(\tilde{r}_{2}\right)$.

Defining $r_{\alpha \rho}=-\left(\mu+u_{\alpha} \sigma \sqrt{\frac{1+\rho}{2}}\right)$ yields equation (6).

\section{References}

Bessis, J. (2002). Risk management in banking. Chichester, UK: John Wiley \& Sons.

Broll, U., Eckwert, B., Eickhoff, A. (2012). Financial intermediation and endogenous risk in the banking sector. Economic Modelling, 29(5), 1618-1622.

Broll, U., Wong, K. P. (2010). Banking firm and hedging over the business cycle. Portuguese Economic Journal, 9(1), 29-33.

Czarniawska, B. (2012). Operational risk, translation, and globalization. Contemporary Economics, 6(2), 26-39.

Duffie, D., Pan, J. (1997). An overview of value at risk, The Journal of Derivatives, 4(3), 7-49.

Freixas, X., Rochet, J.-C. (2008). Microeconomics of banking. Cambridge, MA: The MIT Press.

Frenkel, M., Hommel, U., Rudolf, M. (2005). Risk management: challenge and opportunity, Berlin: Springer Verlag.

Greenbaum, S. I., Thakor, A. V. (2007). Contemporary financial intermediation. Forth Worth, TX: Academic Press.

Jorion, P. (2006). Value at risk: the new benchmark for controlling market risk. New York, NY: McGraw-Hill.

Saunders, A., Allen, L. (2002). Credit risk measurement: new approaches to value at risk and other paradigms, New York, NY: Willey and Sons.

Simons, K. (2000). The use of value at risk by institutional investors, New England Economic Review, Nov./Dec., 21-30.

Wong, K. P. (1997). On the determinants of bank interest margin under credit and interest rate risks. Journal of Banking and Finance, 21(2), 251-271.

Wong, K. P. (2011). Regret theory and the banking firm: The optimal bank interest margin. Economic Modelling, 28(6), 2483-2487. 